\title{
Geriatric Nutrition: Need for Better Ageing
}

\author{
Kirti M. Tripathi, Yashvant Singh ${ }^{1}$,S. K. Dubey ${ }^{2}$ and Thiru Sevan ${ }^{3}$ \\ Krishi Vigyan Kendra, Bulandshahr, SVPUAT, Meerut \\ ${ }^{1}$ Deptt. of Radiology, PGIMER \& Dr. RML Hospital, New Delhi \\ ${ }^{2}$ ICAR- ATARI, Zone IV, Kanpur \\ ${ }^{3}$ Department of Forestry and Biodiversity, Tripura University, Agartala
}

\begin{abstract}
Old age is one of the vulnerable and prone stages in terms of health status. Nutrition is essential determining factor of elderly mass specifically over the age of 60 years. Geriatric nutrition has been always underreported, though everyone wants to make the senescence easy. Adequate nutrition is always important for better ageing. Physical activities are also in the same queue of building the ageing an easier process. Health conditions like hypertension, cholesterol, renal failure, joint problems and cardiac problems should be taken into consideration before starting any kind of physical activity. Therapeutic diets should be inculcated in any kind of bodily ailment. It is found that in India elderly are usually suffered from micro nutrient deficiency, which should also be given emphasis. Scarcity of awareness, prejudice, depression and loneliness are some of the factors behind the increased vulnerability of nutritional deficiency related ailments. Small interventions can make the ageing better.
\end{abstract}

Keywords: Geriatric, nutrition, ageing, Therapeutic.

Paper cited: Tripathi, K.M., Singh, Y., Dubey, S.K. and Seven, T. (2016). Geriatric Nutrition: Need for Better Ageing. South Asian Journal of Food Technology and Environment, 2(3\&4): 432-437.

\section{Introduction}

Ageing gracefully is an art. It requires lot of awareness, motivation and support, physically, mentally and socially. It is found in the study that by 2050 , around 30 percent of people in industrialised countries will be over 65 years. But, tremendous rise in chronic diseases is increasing the risk of related disorders in elderly. Malnutrition leads to decreased independence due to physical weakness and muscle wasting. It frequently leads to falls and fractures. In India $50 \%$ of the elderly population is malnourished. Balanced nutrient is very important for overall wellbeing. It becomes still important in perspective of elderly masses due to physiological changes in the body. Immunity weakens with proceeding age which is influenced by lack of nutrients and differed dietary habits (Grubeck-Loebenstien et al., 2002). Elderly are more prone to several infections also (Gavazzi et al., 2002).
Dentition, taste, smell, loss of memory and Parkinson disorders also influence food intake. A lower food intake among those who live alone may be affected by both functional capacities (including fatigue and mobility) and loneliness. Study has shown that elderly people living with their partners living in a better way than those without partner (Barette et al., 2006). As people age, adequate nutrition propels the maintenance of health, physical performance and psychological wellbeing (Bates et al., 2002 and Nijs et al., 2006). Poor nutritional status refers to an inadequate or even excessive intake or utilisation of the nutrients to meet the body's requirements (Joshi, 2010).

Multi-morbidity associated with increasing age is common and is found to be more frequent in developing countries (Joshi et al., 2003). In India, geriatric age group (aged 60 years and above) constitute $8.6 \%$ of the total population as per 2011 census. Majority of them 
lives in rural India (Bhat and Dhruvarajan, 2001). The magnitude of malnutrition among the elderly in India is underreported. Studies have shown that more than $50 \%$ of the older population is underweight (Natarajan et al., 1995) and more than $90 \%$ has an energy intake below the recommended allowance (Natarajan et al., 1993).

\section{Physiological changes during aging}

Once the body reaches physiological maturity, the rate of degenerative change exceeds the rate of cell regeneration. However, people age at different rates, so the elderly population is not a homogenous group. Body composition changes as fat replaces muscle, in a process called sacropenia. A study shows that exercise, particularly weight training, slows down this process. It is also seen that basal metabolic rate (BMR) declines about $5 \%$ per decade during adulthood. Body water decreases with the drop in caloric needs and lowered protein reserves.
It is seen in the studies that with progressive age digestive hormones decreases and so the enzymes. Constipation is the major problem faced by elderly. A progressive drop in bone mass starts when people are in their 30s and 40s; this accelerates during menopause for women resulting in fractures and osteoporosis. Decrease in all the senses, particularly in the taste buds that affect appetite. Denture wearers chew less efficiently than those with natural teeth. Insulin secretion usually decreases, which can lead to carbohydrate intolerance, and renal function deteriorates in the 40s for some people. Recent research has also demonstrated that distant experiences such as childhood personality and education, as well as behavioural factors, also contribute to longevity (Martin et al., 2011). It is generally accepted that the aging process falls physiologically into three groups of changes that occur with advancing age (Dodds, 2006).

Equations for calculation of predicted basal metabolic rate (PBMR)

Harris- Benedict equation (kcal/day)

$$
\begin{aligned}
& \text { Males: } 66.473+(13.7516 * \mathrm{Wt})+(5.0033 * \mathrm{Ht})-\left(6.755^{*} \text { age }\right) \\
& \text { Females: } 665.0955+(9.5634 * \mathrm{Wt})+(1.8496 * \mathrm{Ht})-(4.6756 * \text { age })
\end{aligned}
$$

Reduced sodium intakes become important, as blood pressure tend to increases in women over age 60 . Serum cholesterol levels peak for men at age 60 but continue to rise in women until age 70. Immunity decreases with progressing age and make the body less able to fight infections and malignancies. Vitamin E, zinc, and some other supplements may increase immune functions.

\section{Psychosocial changes that occur during aginig}

Physical illnesses and poverty were significantly correlated with geriatric depression, as in other studies (Cole and Dendukuri, 2003; Osborn et al., 2003; Sherina et al., 2004; Tsai et al., 2005; Chi et al., 2005; Khattri and Nepal, 2006; Jain and Aras, 2007; Kaneko et al., 2007). The depressed individuals in low-income communities rarely subscribe to biomedical causal models and hold more to psychosocial as well as interpersonal explanatory models for depression (Pereira et al., 2007). The meager expectations by families of their elderly relatives may also contribute towards high tolerance of depressive symptoms and functional impairment (Jacob et al., 2007). The relationship between poverty, social isolation, physical health and mental health is complex (Kuruvilla and Jacob, 2007). Depression, the most common cause of unexplained weight loss in older adults, occurs 
in approximately $15 \%$ of adults over age 65 , with a much higher incidence in those living in extended care facilities.

Memory impairment caused by
various types of dementia, Alzheimer's
disease, or other neurological diseases rises
markedly. Social isolation becomes a big
problem among elderly due to declining
income, health problems and loss of spouse or
friends. These all may affect appetite and thus
resulting in poor nutritional status.

\section{Nutritional requirement in aging}

Calorie requirement decreases with age, although individuals vary greatly depending on their activity level and nutritional status. Whole day diet should contain 1800 calories but again depend on the health status. Protein needs of healthy older adult are same as other adults. The basic requirement is $0.8-1.0 \mathrm{~g}$ protein $/ \mathrm{kg}$ of body weight. Green leafy vegetables, other vegetables and fresh fruits are treasure trove of several minerals and vitamins and hence, protect from diseases. Excessive use of plant and animal based fats elevation of blood lipids thereby increasing the risk of heart disease and other illnesses.

Eat foods rich in alpha-linolenic (ALA) acid such as legumes, green leafy vegetables, fenugreek and mustard seeds. Higher sodium intake leads to greater calcium excretion which may result in reduction in bone density. Existing evidence reveals a deleterious impact of high salt intake on blood vessels, blood pressure, bones and gastrointestinal tract. Salt intake in our population generally exceeds the requirement. It should not be more than $6 \mathrm{~g}$ per day. Salt is used as a vehicle for food fortification since it is commonly used in food preparation. The antioxidant vitamins, vitamin $\mathrm{E}$, carotenoids and vitamin $\mathrm{C}$, continue to receive attention because of their potential to improve immune functions. Need for vitamin A decreases and that of riboflavin, vitamin $\mathrm{B} 6$ and $\mathrm{B} 12$ and zinc increases.

A diet consisting of foods from several food groups provides all the required nutrients in proper amounts. They help in prevention of micronutrient malnutrition and certain chronic diseases such as cardiovascular diseases, cataract and cancer. Fresh fruits are nutritionally superior to fruit juices. Overweight and obese individuals are at an enhanced risk of co-morbidities including type 2 diabetes, fatty liver disease, gallstones, high blood cholesterol and triglycerides, orthopaedic disorders (Osteoarthritis), hypertension and other cardiovascular diseases, certain cancers and psycho-social problems. Eat variety of foods to ensure a balanced diet. Processed foods being rich in fats, salt, sugar and preservatives may pose a health risk if consumed regularly. Water is the most important nutrient of all and helps in the upkeep of our health. Adequate water-intake guidelines are $1.0 \mathrm{ml}$ water/kcal energy consumed (for example, 1.8 L for a 1,800calorie intake), or $25-30 \mathrm{ml} / \mathrm{kg}$ of weight for most individuals. Healthy and positive food concepts and cooking practices are foundation for good health. Senior citizens need more of vitamins and minerals to remain healthy and active. Elderly should try to incorporate variety of nutrient-rich foods. They should maintain the balance of food intake with physical activity. Eat food in many divided portions in a day. Food with more oil and spices should be avoided.

Body movements are essential in elderly in the form of exercises like walk, yoga etc regularly. This controls the body weight and composition, reduces risk chronic diseases, such as Type 2 diabetes, high blood pressure, heart disease, osteoporosis, arthritis and certain types of cancers. It also help in building strong muscles, bones and joints, improves flexibility, wards off depression, improves mood, sense of well-being and self esteem. Men over 40 and women over 50 
should also consult doctor or health care provider before starting a vigorous physical activity program. Cholesterol content of various foods is shown in Table 1.

Table 1: Cholesterol Content of various foods

\begin{tabular}{lcc|}
\hline Items & Quantity & mg \\
\hline Egg & 1 & 250 \\
Meat & $100 \mathrm{~g}$ & 135 \\
Cheese & $100 \mathrm{~g}$ & 56 \\
Liver & $100 \mathrm{~g}$ & 400 \\
Milk & $200 \mathrm{~g}$ & 45 \\
Skimmed milk & $200 \mathrm{~g}$ & 5 \\
Ice cream & $100 \mathrm{~g}$ & 54 \\
\hline
\end{tabular}

\section{Dietary Guidelines}

Variety of whole grains, millets and pulses should be included in the daily diet. Two Glasses $(1$ glass $=240 \mathrm{ml})$ of low fat milk and equivalent milk products should be included in the diet. About 4 - 5 servings of fruits and vegetables (all colors) should be included ( 1 serving $=1$ bowl $=125 \mathrm{~g}$ ). Encourage intake of salads. 15 - $20 \mathrm{~g}$ of healthy oil (low Saturated Fatty Acids and Trans Fatty Acids) is recommended. Promote alternate oils. Substitute nuts and oilseeds in place of fats and oils. For non-vegetarians egg white, lean chicken and fish is recommended

\section{Behaviour Guidelines}

Elderly should incorporate small frequent meals at regular intervals. Gap between 2 meals should not be less than 3 hours. Emphasis should be on not to skip breakfast and have early dinner choose healthy snack options. Follow the healthy dietary guidelines while eating out. Boiled / steamed / roasted / grilled cooking methods should be preferred over frying Alcohol is not under recommendation.

\section{Food based guidelines}

Consume a wide variety of foods across all food groups and a wide selection within each of these groups. Consume nutrient dense foods like fruits, vegetables, wholegrain cereals and pulses, low-fat milk and dairy products, nuts, soybean products, fish etc.
Emphasize healthy traditional dishes: dal palak, dal methi, sprouts chat, vegetable raita, missi roti, carrot halwa with nuts to name a few. Encourage consumption of available protective foods (fish, nuts,garlic, onion, cruciferous and leafy vegetables, tomatoes, soy, other pulses, citrus fruits, grapes, berries, herbs, spices and green tea etc. Limit traditional dishes/foods like mithai, cream pastries, balushahi, achars heavily preserved/pickled in salt, or fried bhaturas , mathi, kachodi, dalmoth, patties etc. Consume mono-unsaturated and poly-unsaturated dietary visible fats obtained from mustard, ricebran, soybean, safflower, groundnut,sunflower, til, and limit fatty spreads in cooking or on bread containing saturated fats and trans fats. Minimize or combine foods containing hidden animal fats (fatty meat, full-fat dairy products, some fast/processed food, and hydrogenated plant fats (some fast/processed food, commercial cakes/biscuits). Limit visible oil consumption to about 20g/day. Added oils may assist in the absorption of fat soluble nutrients and phytochemicals from plant foods. Consume a variety of fats for cooking which have been minimally processed (cold pressed or 'extra virgin'). Enjoy food and eating in the company of others, but avoid the regular use of energy dense (nutrient poor) celebratory foods and beverages which are high in fat and or sugar. 


\section{Conclusion}

Considering the high prevalence of poor nutritional status among elderly, more focus on diet and possible nutritional interventions are required. Like other ages, old age is also very important in terms of better movement of life towards senescence. Elderly require more attention for better physiological and psychosocial progression. Lower income group should receive particular attention to meet their special needs. Any kind of physical activity is required for maintaining hypertension, diabetes and cardiac problems. Vitamins and minerals being protective in nature should be introduced in the diet to fight with infections and malignancies. The promotion and implementation of low cost, prevention-based initiatives such as health, nutrition, and physical education, could significantly enhance the possibility of maintaining good nutritional status for the elderly.

\section{References}

1. Barrett, P., Twitchin, S. and Kletchko, S. (2006). The living environments of community-dwelling older people who become frail: another book at the Living Standards of Older New Zealanders Survey. Social Policy Journal of New Zealand, 28: 133-157.

2. Bates, C.J., Benton, D., Biesalski, H.K., Staehelin, H.B., Staveren, W., Stehle, P., Suter, P.M. and Wolfram, G. (2002). Nutrition and Aging: A Consensus Statement. Journal of Natural Health Aging, 6:103-160.

3. Bhat, A.K., Dhruvarajan, R. (2001). Ageing in India: drifting intergenerational relations, challenges and options. Ageing and Society, 21: 621-640.

4. Chi, I, Yip, P.S., Chiu, H.F., Chou, K.L., Chan, K.S., Kwan, C.W., Conwell, Y. and Caine, E. (2005). Prevalence of depression and its correlates in Hong
Kong's Chinese older adults. American Journal of Geriatric Psychiatry, 13: 409-416.

5. Cole, M. G. and Dendukuri, N. (2003). Risk factors for depression among elderly community subjects: a systematic review and meta-analysis. American Journal of Psychiatry, 160: 1147-1156.

6. Dodds, C. (2006). Physiology of ageing. Anaesthesia \& Intensive Care Medicine, 7(12): 456-458.

7. Gavazzi, G. and Krause, K.H. (2004). Ageing and infection. Lancet Infectious Diseases, 2: 659.

8. Grubeck-Loebenstein, B., Berger, P., Saurwein-Teissl, M., Zisterer, K. and Wick, G. (1998). No immunity for the elderly. Nature Medicine, 4: 870.

9. Jacob, K.S., Senthil Kumar, P., Gayathri, K., Abraham, S. and Prince, M. J. (2007). Can health workers diagnose dementia in the community? Acta Psychiatrica Scandinavica, 116: 125-128.

10. Jain, R.K. and Aras, R.Y. (2007). Depression in geriatric population in urban slums of Mumbai. Indian Journal of Public Health, 51: 112-113.

11. Joshi, K., Kumar, R. and Avasthi, A. (2003). Morbidity profile and its relationship with disability and psychological distress among elderly people in Northern India. International Journal of Epidemiology, 32: 978-987.

12. Joshi, S. A. (2010). Nutrition and Dietetics. Introduction to Nutrition and Dietetics, pp 5.

13. Kaneko, Y., Motohashi, Y., Sasaki, H. and Yamaji, M. (2007). Prevalence of depressive symptoms and related risk factors for depressive symptoms among elderly persons living in a rural Japanese community: a cross-sectional study. Community Mental Health Journal, 43: 583-590. 
14. Khattri, J.B. and Nepal, M.K. (2006). Study of depression among geriatric population in Nepal. Nepal Medical College Journal, 8: 220-223.

15. Kuruvilla, A. and Jacb, K.S. (2007). Poverty, Social stress \& Mental Health. Indian Journal of medical Research, 126: 273-278.

16. Martin, P., Poon, L.W., and Hagberg, B. (2011). Editorial - Behavioral factors of longevity. Journal of Aging Research, 2011, 1-2. doi: 10.4061/2011/197590

17. Natarajan, V.S., Shanthi, R. and Krishnaswamy, B. (1995). High prevalence of nutritional disorders and nutrient deficits in elderly people in a rural community in Tamil Nadu, India. Journal of the Hong Kong Geriatrics Society, 6: 40-43.

18. Natarajan, V.S., Shanthi, R., Sivashanmugam., Thyagarajan., Kailash, K. and Krishnaswamy, B. (1993). Assessment of nutrient intake and associated factors in an Indian elderly population. Age Ageing, 22: 103-108.

19. Nijs, K.A., de Graaf, C., Siebelink, E., Blauw, Y.H., Vanneste, V., Kok, F.J. and van Staveren, W.A. (2006). Effect of family-style meals on energy intake and risk of malnutrition in dutch nursing home residents: a randomized controlled Trial. The Journals of Gerontology. Series A, Biological Sciences and Medical Sciences, 61: 935-42b.
20. Osborn, D.P., Fletcher, A.E., Smeeth, L., Stirling, S., Bulpitt, C.J., Breeze, E., Ng, E.S., Nunes, M., Jones, D. and Tulloch, A. (2003). Factors associated with depression in a representative sample of 14,217 people aged 75 and over in the United Kingdom: results from the MRC trial of assessment and management of older people in the community. International Journal of Geriatric Psychiatry, 18: 623-630.

21. Pereira, B., Andrew, G., Pednekar, S., Pai, R., Pelto, P. and Patel, V. (2007). The explanatory models of depression in low-income countries: listening to women in India. Journal of Affective Disorders, 102: 209-218.

22. Sherina, M.S., Rampal, L. and Mustaqim, A. (2004). The prevalence of depression among the elderly in Sepang, Selangor. Medical Journal of Malaysia, 59: 45-49.

23. Tsai, Y.F., Yeh, S.H. and Tsai, H.H. (2005). Prevalence and risk factors for depressive symptoms among community-dwelling elders in Taiwan. International Journal of Geriatric Psychiatry, 20: 1097-1102. 